\title{
Severity of scleroderma lung disease is related to alveolar concentration of
} nitric oxide

\author{
K.P. Tiev*, J. Cabane*, F. Aubourg* , A. Kettaneh*, M. Ziani*, L. Mouthon ", \\ S. Duong-Quy" ${ }^{\#}$ I. Fajac ${ }^{\#}$, L. Guillevin ${ }^{\star}$ and A.T. Dinh-Xuan\#
}

ABSTRACT: The alveolar concentration of exhaled nitric oxide $(C A, N O)$ is increased in patients with systemic sclerosis (SSc), but whether this increase is related to the severity of interstitial lung disease (ILD) in SSc has not yet been investigated.

In total, 58 SSc patients prospectively underwent pulmonary function tests (PFTs), echocardiogram and fibrosis scoring on pulmonary computed tomography (CT). Patients were divided into two groups according to the presence (or not) of ILD. Measurements of CA,NO were assessed in all SSc patients and compared with those obtained in 19 healthy volunteers. Relationships were sought between CA,NO PFTs and CT scan fibrosis scores.

Overall, CA,NO was significantly increased in SSc patients (median (range) 6.2 (3.8-9.9) ppb) as compared with controls (2.0 (1.2-3.0) ppb). Among SSc patients, CA,NO was significantly higher in patients with ILD compared with patients without ILD $(n=33,7.5$ (5.2-11.9) ppb versus $n=25$, 4.9 (3.1-7.0) ppb, respectively). CA,NO was inversely related to total lung capacity $(r=-0.34)$ and the diffusing capacity of the lung for carbon monoxide $(r=-0.37)$ and was directly related to CT scan fibrosis scores $(r=0.36)$.

An increased alveolar concentration of exhaled nitric oxide could, at least in part, either reflect or contribute to the severity of lung disease and could be used to noninvasively assess the extent of interstitial lung disease in systemic sclerosis.

KEYWORDS: Exhaled nitric oxide, interstitial lung disease, nitric oxide, systemic sclerosis

ystemic sclerosis (SSc) is a multi-system disorder of unknown aetiology. It is characterised by fibrosis of the skin and organs including the lungs, heart, gastrointestinal tract and kidneys [1]. Interstitial lung disease (ILD) occurs in $35-40 \%$ of patients with SSc. Multiple factors such as oxidative stress and chronic inflammation may be responsible for lung injury leading to pulmonary fibrosis, resulting in restrictive lung function and reduced gas lung transfer. The extent of ILD can be evaluated by pulmonary computed tomography (CT), which shows ground-glass attenuation or a reticular fibrosis aspect that are related to the presence of unknown interstitial pneumonia or nonspecific interstitial pneumonia in pathological pulmonary biopsy specimens [2, 3]. These CT scan signs, particularly ground-glass attenuation, could reflect the area of the active pulmonary lesion in SSc [4]. The pathogenetic aspects of scleroderma lung disease remains unclear and the reversibility of ILD with treatment is uncommon in SSc. Currently, assessment of lung involvement or prognosis in SSc is often difficult and unreliable, with direct evidence of alveolitis or detailed histological diagnosis only provided by invasive means, such as bronchoscopy and bronchoalveolar lavage (BAL) cell count [5] or transbronchial biopsy, which are difficult to perform on a regular basis. Hence, there is a need to develop noninvasive tools with which to assess severity of lung impairment in SSc.

Partitioning of nitric oxide (NO) in the exhaled air $[6,7]$, into alveolar concentration of exhaled $\mathrm{NO}(\mathrm{CA}, \mathrm{NO})$ and conducting airway flux $\left(J^{\prime}\right.$ aw,NO), can differentiate the anatomic origin of the inflammation, i.e. distinguishing alveoli from inflammatory airways disorders, thus providing a useful tool with which to evaluate the local NO production in respiratory disease. $\mathrm{CA}, \mathrm{NO}$ is increased in patients with SSc and ILD [8]. However, it has not yet been investigated as to whether this increase actually reflects the importance of functional lung impairment and the extent of morphological lung involvement in
AFFILIATIONS

*Dept of Internal Medicine, Faculty of Medicine, Université Paris Pierre et Marie Curie, Hôpital Saint-Antoine, and

Depts of ${ }^{\#}$ Respiratory Physiology and

Internal Medicine, Faculty of Medicine, Université Paris Descartes, Hôpital Cochin, Paris, France.

CORRESPONDENCE

A.T. Dinh-Xuan

Dept of Respiratory Physiology

Faculty of Medicine

EA 2511

Université Paris Descartes

Hôpital Cochin

27 rue du faubourg Saint-Jacques

75679

Paris Cedex 14

France

Fax: 33158412345

E-mail: anh-tuan.dinh-xuan@

cch.aphp.fr

Received:

October 042006

Accepted after revision:

March 252007

SUPPORT STATEMENT

The present study was supported by the Association des Sclérodermiques de France, 59930 La Chapelle d'Armentiéres, France.

STATEMENT OF INTEREST

None declared. 
SSc. Therefore, the aim of the current study was to investigate the relationship between exhaled NO (eNO) levels, detailed lung function testing and high resolution CT fibrosis-scoring in SSc patients. The current authors hypothesised that the degree of lung involvement as assessed by eNO could reflect the extent of ILD in SSc.

\section{METHODS}

\section{Subjects}

Between November 2004 and December 2005, 58 patients (52 females, six males, median age (1st-3rd quartile) 53.5 (4560) yrs) who met the American College of Rheumatology criteria for SSc [9], were included in the prospective study conducted in two academic SSc referral centres in France (Hôpital Saint-Antoine and Hôpital Cochin, both Paris). Clinical data, including a modified Rodnan skin score, were collected from all SSc patients (table 1). Patients were divided into two groups according to the presence (or not) of ILD documented by pulmonary CT. In total, 33 SSc patients (55.8 (47.3-60.8) yrs) had ILD and 25 patients (52.4 (44.7-59.0) yrs) had no ILD (table 2). Patients with a recent respiratory tract infection ( $<3$ months) and patients receiving immunosuppressive treatment (cyclophosphamide, mycophenolate mofetil), corticosteroids $>10 \mathrm{mg} \cdot$ day $^{-1}$ or bosentan, were excluded from the present study. Among the 58 enrolled patients with SSc, 11 received low dose corticosteroids $\left(5-10 \mathrm{mg} \cdot \mathrm{day}^{-1}\right)$, and 10 were current smokers. None of the SSc patients had a history of atopy or took NO donors. Measurement of the diffusing capacity of the lung for carbon monoxide $(D \mathrm{~L}, \mathrm{CO})$ could not be performed in two SSc patients. eNO was measured in all SSc patients and in 19 healthy nonsmoking controls (nine females, 10 males, aged 42.7 (28.1-50.4) yrs). This study was approved by the local ethics committee and all subjects provided informed consent.

\section{Pulmonary CT scanning}

All patients underwent a high-resolution CT (HRCT) scan of the lungs in the week prior the measurement of eNO. ILD was considered present if the HRCT scan of the chest demonstrated compatible changes in reticular or air-space opacities. The extent of the individual CT scan patterns was estimated in each lobe with five levels of scoring for ground glass and fibrosis [10] as follows: 0) no abnormality; 1) $<5 \%$ of the lobe; 2) $6-25 \%$ of the lobe; 3) $26-50 \%$ of the lobe; 4) $51-75 \%$ of the lobe; and 5) $76-100 \%$ of the lobe. Ground-glass attenuation was defined as a hazy increase of lung parenchymal attenuation and fibrosis score included lobular septal thickening and subpleural honeycomb change.

\section{Echocardiogram}

All patients underwent an echocardiogram (Vivid ${ }_{\circledR}$ 7; G.E Medical Systems, Horten, Norway) in the week prior to measurement of eNO. Pulmonary hypertension was defined by a right ventricular systolic pressure of $>40 \mathrm{mmHg}$ on echocardiogram.

\section{Lung function measurement}

Pulmonary function tests (PFT; forced vital capacity, forced expiratory volume in one second), DL,CO (MasterScreen ${ }^{\circledR}$ Body; VIASYS Healthcare GmbH, Hoechberg, Germany) and

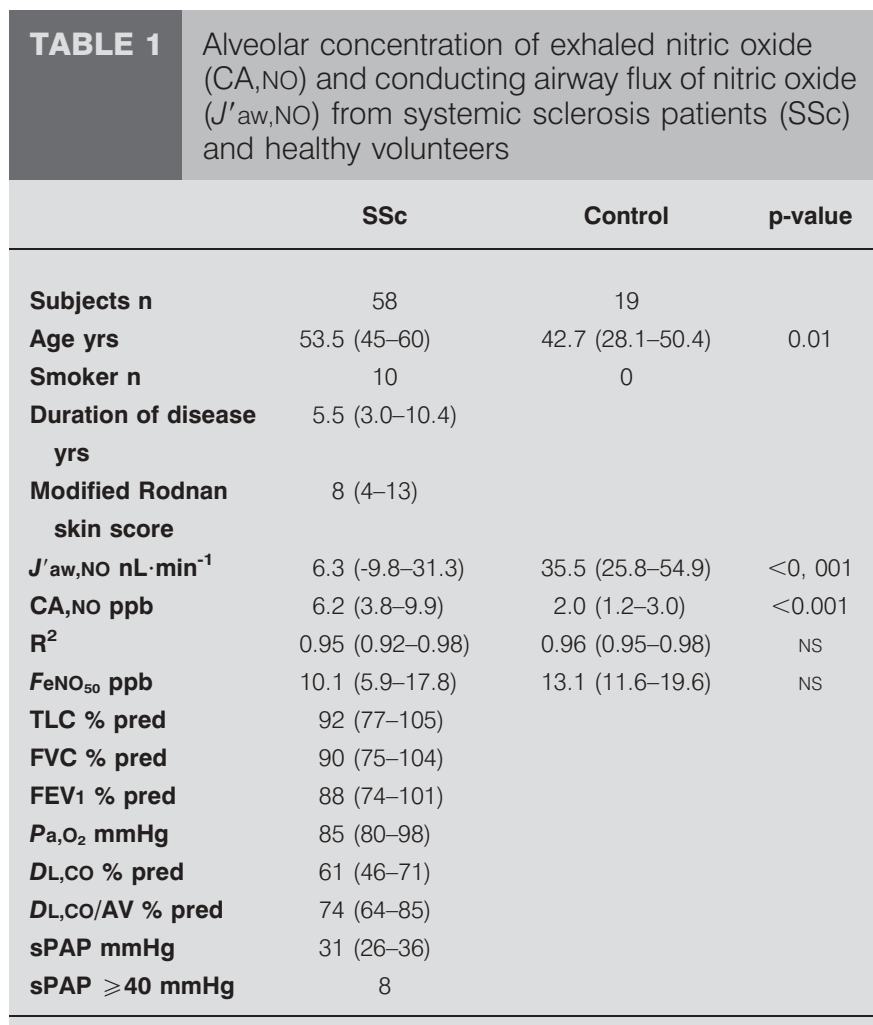

Data are presented as median (1st-3rd quartile), unless otherwise stated. $R^{2}$ relationship between the elimination rate of nitric oxide (NO) and exhalation flow rate; $\mathrm{FeNO}_{50}$ : fractional exhaled $\mathrm{NO}$ concentration at $50 \mathrm{~mL} \cdot \mathrm{s}^{-1}$ constant flow rate; TLC: total lung capacity; \% pred: \% predicted; FVC: forced vital capacity; FEV1: forced expiratory volume in one second; $\mathrm{Pa}_{\mathrm{a}_{2}}$ : arterial oxygen tension $\mathrm{LL}, \mathrm{CO}$ : diffusing capacity of the lung for carbon monoxide; $\mathrm{AV}$ : alveolar volume; SPAP: systolic pulmonary artery pressure; NS: nonsignificant. $1 \mathrm{mmHg}=$ $0.133 \mathrm{kPa}$

blood gas measurement were performed. PFT parameters were expressed as percentage of predicted normal values [11].

\section{Fractional exhaled NO measurement}

NO was measured using a chemiluminescent NO analyser (EndoNO 8000 ${ }_{\circledast}$; SERES, Aix-en-Provence, France), according to a validated method for the online measurement of the exhaled NO fraction (FeNO) in adults [12]. After full inspiration on room air with ambient NO levels $<20$ parts $\cdot$ billion $^{-1}(\mathrm{ppb})$, the subject exhaled against a positive pressure that was constantly kept between $5-20 \mathrm{cmH}_{2} \mathrm{O}$ to generate exhalation flow rates (EFR) of 50, 100, 150 and $200 \mathrm{~mL} \cdot \mathrm{s}^{-1}$. For each EFR, the elimination rate of $\mathrm{NO}(\mathrm{ERNO})$ was calculated as $\mathrm{ERNO}=$ $\mathrm{EFR} \times \mathrm{FeNO}[6,7]$. FeNO is inversely related to EFR, whereas ERNO varies directly as a function of EFR. At a flow rate $>50 \mathrm{~mL} \cdot \mathrm{s}^{-1}$, the latter relationship is linear and can be expressed as $\mathrm{ERNO}=\mathrm{EFR} \times \mathrm{FeNO}=\mathrm{CA}, \mathrm{NO} \times \mathrm{EFR}+J^{\prime}$ aw, $\mathrm{NO}[6,7]$. For each patient and control, the $\mathrm{R}^{2}$ values of the relationship between FeNO and EFR were calculated.

\section{Statistical analysis}

All results are expressed as median (1st-3rd quartile). Comparisons between the two SSc groups (with and without ILD) and controls were performed by Kruskal-Wallis test. 


\begin{tabular}{|c|c|c|c|}
\hline \multirow[t]{3}{*}{ TABLE 2} & $\begin{array}{l}\text { nitric oxide (N } \\
\text { s (SSC) patient } \\
\text { al lung disease }\end{array}$ & $\begin{array}{l}\text { levels from s) } \\
\text { with and witho } \\
\text { (ILD) }\end{array}$ & temic \\
\hline & \multicolumn{2}{|c|}{ SSc } & \multirow[t]{2}{*}{ p-value } \\
\hline & With ILD & Without ILD & \\
\hline Subjects $\mathrm{n}$ & 33 & 25 & \\
\hline Age yrs & $55.8(47.3-60.8)$ & $52.4(44.7-59.0)$ & NS \\
\hline Smoker $\mathbf{n}$ & 4 & 6 & NS \\
\hline$J^{\prime}$ aw,NO $\mathrm{nL} \cdot \mathrm{min}^{-1}$ & $4.1(-18.9-13.6)$ & $18.0(-0.2-39.6)$ & $<0.05$ \\
\hline CA,NO ppb & $7.5(5.2-11.9)$ & $4.9(3.1-7.0)$ & $<0.01$ \\
\hline $\mathrm{R}^{2}$ & $0.96(0.92-0.98)$ & $0,95(0.93-0.98)$ & NS \\
\hline $\mathrm{FeNO}_{50} \mathrm{ppb}$ & $9.3(5.8-17.1)$ & $11.1(6.1-19.0)$ & NS \\
\hline TLC \% pred & $82(68-95)$ & $105(90-107)$ & $<0.001$ \\
\hline FVC \% pred & $81(70-97)$ & $97(83-115)$ & $<0.01$ \\
\hline FEV $_{1} \%$ pred & $83(74-100)$ & $92(83-105)$ & NS \\
\hline $\mathrm{Pa}, \mathrm{O}_{2} \mathrm{mmHg}$ & $84(79-98)$ & $86(82-97)$ & NS \\
\hline DL,Co \% pred & $53(42-66)$ & $65(59-82)$ & $<0.01$ \\
\hline DL,Co/AV \% pred & $73(58-82.7)$ & $76(71-85)$ & NS \\
\hline Ground-glass score ${ }^{\#}$ & $8(6-12)$ & $0(0-0)$ & $<0.001$ \\
\hline Reticular score s $^{\#}$ & $7(4-9)$ & $0(0-0)$ & $<0.001$ \\
\hline
\end{tabular}

Data are presented as median (1st-3rd quartile), unless otherwise stated. $R^{2}$ : relationship between the elimination rate of $\mathrm{NO}$ and exhalation flow rate; $\mathrm{FeNO}_{50}$ : fractional exhaled NO concentration at $50 \mathrm{~mL} \cdot \mathrm{s}^{-1}$ constant flow rate; TLC: total lung capacity; \% pred: \% predicted; FVC: forced vital capacity; FEV1: forced expiratory volume in one second; $\mathrm{Pa}, \mathrm{O}_{2}$ : arterial oxygen tension; $\mathrm{D} \mathrm{L}, \mathrm{CO}$ : diffusing capacity of the lung for carbon monoxide; AV: alveolar volume; NS: nonsignificant ${ }^{*}$ : maximum of each score is $25.1 \mathrm{mmHg}=0.133 \mathrm{kPa}$.

Comparisons between SSc patients with and without ILD, and those between patients with pulmonary hypertension and healthy controls were performed by Mann-Whitney U-test. Correlations between CA,NO and total lung capacity (TLC), ground-glass score, fibrosing score and systolic pulmonary arterial pressure (sPAP) were made by Spearman's test. A pvalue $<0.05$ was considered as statistically significant.

\section{RESULTS}

Demographic characteristics and PFT results are presented in table 1. The median CA,NO was significantly increased in the entire SSc group compared with healthy controls $(n=58,6.2$ (3.8-9.9) ppb versus $\mathrm{n}=19,2.0 \quad(1.2-3.0) \mathrm{ppb}$, respectively; $\mathrm{p}<0.001$; table 1 , fig. 1$)$. The median $\mathrm{R}^{2}$ values of the relationship between FeNO versus EFR were 0.95 for patients and 0.96 for controls. The median J'aw,NO of SSc patients was lower than that of healthy controls $\left(\mathrm{n}=58,6.3(-9.8-31.3) \mathrm{nL} \cdot \mathrm{min}^{-1}\right.$ versus $\mathrm{n}=19,35.5(25.8-54.9) \mathrm{nL} \cdot \mathrm{min}^{-1}$, respectively; table 1). FeNO values measured in SSc patients did not significantly differ from those obtained from healthy controls (10.1 (5.9-17.8) versus 13.1 (11.6-19.6), respectively; table 1).

Among the 58 patients with SSc, HRCT images revealed heterogeneous areas of both ground-glass and honeycombing in 33 patients, and were consistent with ILD associated with SSc. TLC was significantly reduced, consistent with restrictive lung disease, in the SSc patients with ILD compared with those without ILD (82 (68-95)\% versus 105 (90-107)\%, respectively; $\mathrm{p}<0.001)$. DL,CO/alveolar volume values were not different between the two groups of SSc patients (table 2). Reticular and ground-glass scores were significantly higher in SSc patients with ILD (7 (4-9) and 8 (6-12), respectively) compared with SSc patients without ILD $(\mathrm{p}<0.001)$. CA,NO was significantly higher in SSc patients with ILD compared with SSc patients without ILD ( $\mathrm{n}=33,7.5$ (5.2-11.9) ppb versus $\mathrm{n}=25,4.9$ (3.17.0) $\mathrm{ppb}$, respectively; $\mathrm{p}<0.01)$. Conversely, J'aw,NO was lower in SSc patients with ILD than in patients without ILD (table 2).

In patients with SSc, CA,NO was inversely related to TLC $(r=-0.34$; $\mathrm{p}<0.01)$ and $\mathrm{DL}, \mathrm{CO}(\mathrm{r}=-0.37, \mathrm{p}<0.01)$. Furthermore, CA,NO was directly related to radiological indexes of lung fibrosis, i.e. ground-glass attenuation score $(\mathrm{r}=0.36 ; \mathrm{p}<0.01)$ and reticular score $(\mathrm{r}=0.33 ; \mathrm{p}<0.05)$.

No correlation was found between sPAP estimated by echocardiogram and CA,NO. Furthermore, the median level of $\mathrm{CA}, \mathrm{NO}$ from SSc patients with pulmonary hypertension $(\mathrm{sPAP} \geqslant 40 \mathrm{mmHg}$ ) was comparable with that from SSc patients whose sPAP was $<40 \mathrm{mmHg}(\mathrm{n}=8,6.9$ (5.9-8.9) ppb versus $n=50,6.0$ (3.4-9.0) ppb, respectively). Note that CA,NO from SSc patients with pulmonary hypertension was significantly higher than that from healthy controls $(n=19 ; 2.0(1.2-$ 3.0) ppb; $\mathrm{p}<0.01)$. The use of low dose corticosteroid, $<10 \mathrm{mg} \cdot$ day $^{-1}$, did not significantly affect the CA,NO treated SSc patients as compared with untreated patients.

\section{DISCUSSION}

The present study demonstrates that CA,NO is significantly increased in SSc patients compared with healthy controls, a result consistent with previous findings using the two compartment model method; partitioning eNO into CA,NO and $J^{\prime}$ aw,NO [8]. The observation that eNO is increased in SSc patients is also consistent with previous studies measuring mixed NO concentration in the exhaled air of scleroderma patients with, or without, ILD [13, 14]. The current authors have also demonstrated that $\mathrm{CA}, \mathrm{NO}$ is inversely related to lung

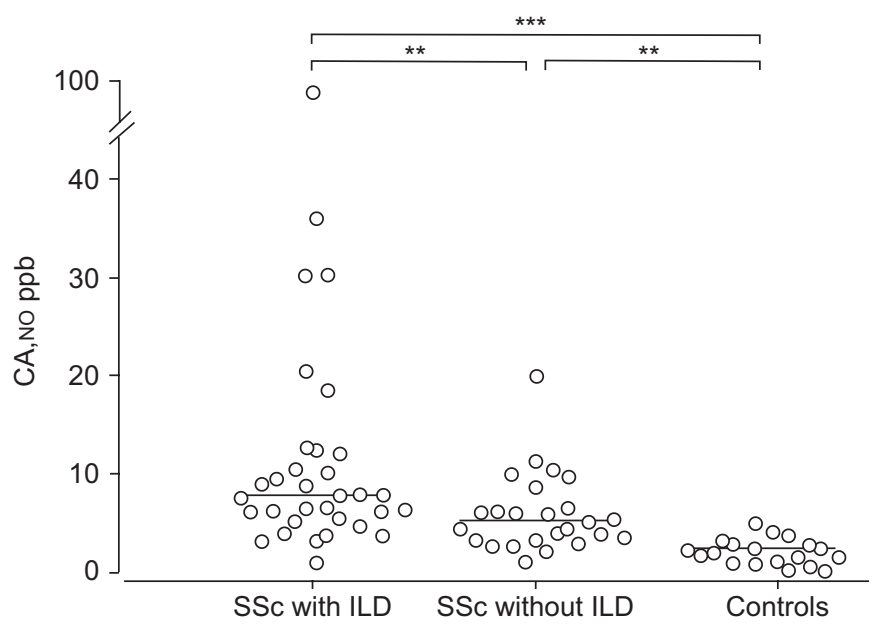

FIGURE 1. Alveolar concentration of nitric oxide $(\mathrm{CA}, \mathrm{NO})$ in healthy controls $(n=19)$ and systemic sclerosis (SSc) patients with $(n=33)$ or without $(n=25)$ interstitial lung disease (ILD). ${ }^{*}: p<0.01 ;{ }^{* *}: p<0.001$, comparisons between the three groups were made with the Kruskal-Wallis test. Horizontal lines represent median values. 
volumes, and directly related to the extent of ILD, as assessed by the ground-glass score and the reticular score on pulmonary CT scans in patients with SSc. Moreover, the present authors have found that the levels of CA,NO are different among SSc patients, being significantly higher in patients with ILD compared with patients without ILD. The low r-values, however, suggest that increased CA,NO only accounts for part of the mechanisms causing lung impairment in SSc patients. The relative importance of $\mathrm{NO}$ with regards to other pathophysiological factors in individual patients, and how its concentration will vary during the time course of the disease are questions that still remain to be addressed.

The inverse correlation between $\mathrm{CA}, \mathrm{NO}$ and $\mathrm{DL}, \mathrm{CO}$ may reflect greater oxidative stress and/or more severe inflammation causing an increase in the alveolar production of NO that results in impaired pulmonary gas transfer. Conversely, reduced gas diffusion (as reflected by low $D \mathrm{~L}, \mathrm{CO}$ ) may in turn account for the accumulation of $\mathrm{NO}$, hence its high concentration in the alveolar compartment. However, DL,CO/alveolar volume values did not significantly differ between patients with versus those without ILD. It is unlikely that diffusion abnormalities could account for increased CA,NO.

No relationship was found between CA,NO and sPAP. The current results are consistent with those from a previous study showing increased eNO in a limited number of SSc patients with pulmonary arterial hypertension [8]. In contrast, by measuring FeNO in mixed expired air, KHARITONOV et al. [15] found decreased eNO in SSc patients with pulmonary hypertension. It is, however, difficult to compare these results with data from the present study due to different methodological approaches used to measure eNO.

Many factors might account for increased pulmonary vascular tone, including overproduction of vasoconstrictors and growth factors [16], inflammatory cytokines [17] or reduced synthesis of pulmonary vasodilators [17, 18]. The current results are consistent with the hypothesis suggesting that pulmonary hypertension in SSc is due, at least in part, to inflammatory processes, rather than reduced endothelial NO synthase activity, as seen in idiopathic pulmonary hypertension [19].

Pulmonary inflammation and lung damage leading to subsequent fibrosis can be assessed by measuring eNO. The present study has shown that CA,NO correlates positively with ground-glass attenuation score and with reticular score, further supporting the association between the severity of ILD and an increased alveolar production of NO.

Together with the increase in $\mathrm{CA}, \mathrm{NO}$, the current authors have found that $J^{\prime}$ aw,NO values are significantly lower in SSc patients compared with those from control subjects. Such a difference has not previously been described. The present authors hypothesise that the low J'aw,NO could reflect reduced NO production in the airways of SSc patients as a result of the inhibitory effects that a high alveolar $\mathrm{NO}$ concentration might exert on bronchial epithelial NO synthase activity [20]. Alternatively, as $\mathrm{CA}, \mathrm{NO}$ and $J^{\prime}$ aw, $\mathrm{NO}$ are derived from the slope and intercept of the linear relationship between EFR and ERNO [6, 7], it is conceivable that the higher the slope, the lower the intercept, based on the two-compartment model of pulmonary NO exchange dynamics [6, 7].
The limitation of the present results relates to the fact that alveolitis was not evidenced by another method, such as bronchoscopy and bronchoalveolar cell count. Such investigations are invasive. Moreover, they could yield false-negative results, for example with BAL cell counts, particularly when alveolitis involves the lower lung lobe [21].

\section{CONCLUSION}

The current authors conclude that alveolar nitric oxide production is significantly increased in patients with systemic sclerosis, probably as a result of a lung fibrosis development. The authors submit that the alveolar concentration of nitric oxide could be used as a surrogate marker for scleroderma lung disease. Furthermore, an increased alveolar concentration of nitric oxide may reflect the extent of lung restriction. The present data highlight the potential interest of this noninvasive method in the diagnosis and the monitoring of interstitial lung disease in patients with systemic sclerosis.

\section{ACKNOWLEDGEMENTS}

The authors would like to thank the technical and nursing staff of the Service de Physiologie-Explorations Fonctionelles (Cochin Hospital, Paris, France) for their technical help.

\section{REFERENCES}

1 Steen VD, Medsger TA Jr. Severe organ involvement in systemic sclerosis with diffuse scleroderma. Arthritis Rheum 2000; 43: 2437-2444.

2 Harrison NK, Myers AR, Corrin B, et al. Structural features of interstitial lung disease in systemic sclerosis. Am Rev Respir Dis 1991; 144: 706-713.

3 Bouros D, Wells AU, Nicholson AG, et al. Histopathologic subsets of fibrosing alveolitis in patients with systemic sclerosis and their relationship to outcome. Am J Respir Crit Care Med 2002; 165: 1581-1586.

4 Rémy-Jardin M, Rémy J, Wallaert B, Bataille D, Hatron PY. Pulmonary involvement in progressive systemic sclerosis: sequential evaluation with CT, pulmonary function tests, and bronchoalveolar lavage. Radiology 1993; 188: 499-506.

5 Behr J, Vogelmeier C, Beinert T, et al. Bronchoalveolar lavage for evaluation and management of scleroderma disease of the lung. Am J Respir Crit Care Med 1996; 154: 400-406.

6 Tsoukias NM, George SC. A two-compartment model of pulmonary nitric oxide exchange dynamics. J Appl Physiol 1998; 85: 653-666.

7 George SC, Högman M, Permutt S, Silkoff PE. Modeling pulmonary nitric oxide exchange. J Appl Physiol 2004; 96: 831-839.

8 Girgis RE, Gugnani MK, Abrams J, Mayes MD. Partitioning of alveolar and conducting airway nitric oxide in scleroderma lung disease. Am J Respir Crit Care Med 2002; 165: 1587-1591.

9 Preliminary criteria for the classification of systemic sclerosis (scleroderma). Subcommittee for scleroderma criteria of the American Rheumatism Association Diagnostic and Therapeutic Criteria Committee. Arthritis Rheum 1980; 23: 581-590.

10 Kazerooni EA, Martinez FJ, Flint A, et al. Thin-section CT obtained at $10-\mathrm{mm}$ increments versus limited three-level 
thin-section CT for idiopathic pulmonary fibrosis: correlation with pathologic scoring. AJR Am J Roentgenol 1997; 169: 977-983.

11 Standardization of spirometry, 1994 Update. American Thoracic Society. Am J Respir Crit Care Med 1995; 152: 1107-1136.

12 American Thoracic Society, European Respiratory Society. ATS/ERS Recommendations for standardized procedures for the online and offline measurement of exhaled lower respiratory nitric oxide and nasal nitric oxide, 2005. Am J Respir Crit Care Med 2005; 171: 912-930.

13 Fajac I, Kahan A, Menkès CJ, Dessanges JF, Dall'AvaSantucci J, Dinh-Xuan AT. Increased nitric oxide in exhaled air in patients with systemic sclerosis. Clin Exp Rheumatol 1998; 16: 547-552.

14 Moodley YP, Lalloo UG. Exhaled nitric oxide is elevated in patients with progressive systemic sclerosis without interstitial lung disease. Chest 2001; 119: 1449-1454.

15 Kharitonov SA, Cailes JB, Black CM, du Bois RM, Barnes PJ. Decreased nitric oxide in the exhaled air of patients with systemic sclerosis with pulmonary hypertension. Thorax 1997; 52: 1051-1055.

16 Farber HW, Loscalzo J. Pulmonary arterial hypertension. N Engl J Med 2004; 351: 1655-1665.

17 Dorfmuller P, Perros F, Balabanian K, Humbert M. Inflammation in pulmonary arterial hypertension. Eur Respir $J$ 2003; 22: 358-363.

18 Dinh-Xuan AT. Endothelial modulation of pulmonary vascular tone. Eur Respir J 1992; 5: 757-762.

19 Giaid A, Saleh D. Reduced expression of endothelial nitric oxide synthase in the lungs of patients with pulmonary hypertension. N Engl J Med 1995; 333: 214-221.

20 Griscavage JM, Hobbs AJ, Ignarro LJ. Negative modulation of nitric oxide synthase by nitric oxide and nitroso compounds. Adv Pharmacol 1995; 34: 215-234.

21 Clements PJ, Goldin JG, Kleerup EC, et al. Regional differences in bronchoalveolar lavage and thoracic high-resolution computed tomography results in dyspneic patients with systemic sclerosis. Arthritis Rheum 2004; 50: 1909-1917. 